\title{
Spatial variation and comprehensive health risk assessment of microbial indoor air quality in microenvironments of North Delhi
}

\section{Pradeep Kumar}

Satyawati College, University of Delhi

A. B. Singh

Institute of Genomics and Integrative Biology

Rajeev Singh ( $\sim 10$ rsingh@gmail.com )

Satyawati College, University of Delhi

\section{Research Article}

Keywords: Microbial air quality, Health survey, respiratory problems, Bacteria, Fungi

Posted Date: April 28th, 2021

DOI: https://doi.org/10.21203/rs.3.rs-445730/v1

License: (c) (i) This work is licensed under a Creative Commons Attribution 4.0 International License.

Read Full License 


\section{Abstract}

The high airborne microbial concentration of indoor areas may be responsible for adverse indoor air quality linked with adverse respiratory and general health effects in the form of Sick building syndromes. The current study aimed to isolate and characterize seasonal (winter and spring) levels of culturable bioaerosols from indoor air and their impact on human health by using an epidemiological health survey. After culturing, microorganisms were identified by standard macro and microbiological protocols followed by biochemical testing and molecular techniques. Sampling results show that bacterial aerosol concentration in the winter season varies from $(300-3650 \mathrm{CFU} / \mathrm{m})$ and fugal aerosols $(300-4150$ $\mathrm{CFU} / \mathrm{m3}$ ) in different microenvironments. However, in spring bacterial aerosols ranged (450-5150 $\mathrm{CFU} / \mathrm{m3}$ ) and fungi (350-5070 CFU/m3). Aspergillus and Cladosporium were major recorded fungi however, Staphylococcus, Streptobacillus, and Micrococcus were major bacterial genera among all the sites. Analysis of the questionnaire survey represented that headache $(28 \%)$ and allergies $(20 \%)$ were major indoor health problems followed by others. Major outcomes of the current study suggested that the elevated levels of bioaerosols are a major risk factor and causing various respiratory health problems. The observed dynamics of this study will help the inhabitants to take precautionary actions to avoid hazardous bioaerosols.

\section{Introduction:}

Indoor air quality plays important role in the health and well-being of people as $80-90 \%$ of the total time is spent in the indoor environment (Reynolds et al 2001). Normal people inhale $10 \mathrm{~m} 3$ air daily which is abundantly populated by various microorganisms in the form of colloidal suspension known as Bioaerosol (Srikanth et al., 2008). Airborne microorganisms (AM) are cosmopolitan and even can be found in the highly controlled environment of operation theatres (Ayoudgu 2010; Ghanizadeh et al., 2012). Fungi are the potential source of allergic problems and general health problems in different ways (Khan and Karuppayil, 2012). Sources of these microorganisms in indoor air may include people, organic dust, storage of various products, and circulation of air through natural and artificial ventilation systems (Bragoszewska et al., 2018 a). Recent studies show that around 30\% of office workers are suffering from problems related to adverse indoor air quality (Szymczak et al 2010). Exposure to these contaminants may cause diseases into three categories: allergic reactions, infections, and intoxication followed by various molecular reactions (Baxi et al., 2016; Fung et al., 2001; Khan et al., 2012; Reijula et al 2004; Husman T, 1996). Respiratory and other health problems in office workers related to the indoor air quality of the built environment are termed as Sick Building Syndrome (SBS) (WHO, 1988). Studies related to Airborne microorganisms along with other air pollutants were given preference by WHO in 2009 (WHO, 2009).

Microbes can adapt themselves in different conditions hence significant variation can be found in concentration in sub-areas of the same microenvironment (Fernsrorm and Goldblatt 2013). Seasonal variation can be shown in the composition and abundance of AM indoor air furthermore, can be associated with the factors such as temperature, relative humidity, and air exchange rate (Frankel et al., 
2012; Kumari et al., 2016; Park et al., 2016). The presence of AM in prenursery schools may also affect the respiratory and pediatric health and well-being of the children (Madamarandawala et al., 2019). Aspergillus, Curvularia, Penicillium, and Rhizopus were the main fungal genera record from the different indoor areas in Kolkata, India (Karmakar et al., 2020). Presence of mycotoxin-producing micromycetes indoor buildings plays a crucial role in causing SBS in occupants (Švajlenka et al., 2017). Hospitals are one of the most important indoor microenvironments spread and propagation of the aero-microflora (Chirca, 2019). An air sampling study conducted in a Hematology hospital by Cho and co-workers reported that the Aspergillus and Penicillium were the most dominant fungal genera in the outdoor and indoor side of buildings (Cho et al., 2019). A questionnaire survey is an efficient method for analyzing the health effects of indoor air quality (Wu et al., 2018). A significant cross-sectional survey was conducted by Herr and co-workers in 2003, represented that waking up due to coughing, coughing, bronchitis, etc. were major recorded problems due to microbial contaminated outdoor air (Herr et al., 2003). Another cross-sectional study conducted in Australia suggested that non-biological activities such as overcrowding, dust, water supply, etc. are associated with the health issues such as respiratory problems/asthma, skin problems, skin problems, etc. in residents (Melody et al., 2016).

Delhi, the national capital city of India is the most polluted city of the country thus attracts more attention from the government and the public. Few studies were conducted in a different part of Delhi to assess the total bacterial and fungal concentration in residential areas and waste dumping sites (Gupta et al., 1993; Ghosh et al., 2013; Kumar et al., 2013). However, previous studies were unable to indicate the possible association between indoor air quality and health issues in different seasons. Questionnaire proforma helped to know the exact health problems in subjects. Seasonal isolation and characterization by using Anderson impactor will help to evaluate the qualitative and quantitative measurement of biocontaminants in suspended particulate matter. Increased or decreased level of a particular biocontaminant and symptoms will help to correlate how they interact with each other and data will be helpful to form new guidelines for the exposure of indoor bio-contaminants.

The objective of this study was to determine the pattern of morbidity among people living in industrial, commercial, and residential due to poor air quality. Another important aspect of the research was to corelate the biological sampling data with health effects and set guidelines to improve problem of ambient air pollution.

\section{Methodology:}

\subsection{Location and characterization of sampling sites:}

Total culturable bacterial and fungal counts were measured in the common residential microenvironments situated in North Delhi from December 2018- May 2019. Delhi is the metropolis and capital of India having a total population of around 19 million. Sampling areas are situated near (around $5 \mathrm{~km}$ ) to the Alipur dumping Yard which spreads biological pollutants by aerosolization of biological waste. Residential houses, College classrooms, lifts, academies, and laboratories of the nearby area of 
Satyawati College were selected for the aerobiological sampling. Sampling localities were divided into three categories residential, commercial, and industrial (Fig. 1).

\subsection{Biological air Sampling:}

Air samples were collected from (July September 2019) by using the conventional settle plate method (passive gravitational method) (Moldoveanu A M 2015). Petri plates containing mycological medium (Sabourd Dextrose agar with Chloramphenicol and Tryptic Soy agar supplemented with cycloheximide). All the samples were collected in the triplicate form and one set of agar plates were also exposed in the open-air environment as control. Samples were collected at the active hours' time so that the highest bioaerosols could be collected. Sampling was performed aseptically in each room at an average height of $1.5 \mathrm{~m}$ (Human breathing height). The fall season was selected for the study because many experimental and epidemiological studies of microbial air quality showed that the highest fungal spores and allergic reactions are caused in this season.

\subsection{Enumeration and Identification of the culturable bioaerosols:}

Culturable bioaerosols from all the microenvironments were cultured on optimum conditions. The plate count method was used for counting the airborne microbes. After sampling samples were transferred to the laboratory aseptically and incubated for cultivation at $37^{\circ} \mathrm{C}$ for $24-36$ hours in case of bacterial samples. For fungal samples the incubation was done at $26-28^{\circ} \mathrm{C}$ for $7-14$ days Indoor \& Outdoor Temperature and Humidity were also recorded during the assessment using the Digital thermometer (Hanna Instruments USA). After incubation, the bacterial and fungal colonies were analyzed by standard procedures. Bacterial colonies were counted by using a colony counter. Microbial growth on agar plates was initially identified by morphology and appearance of colonies, furthermore, Gram's staining was performed followed by Biochemical and Molecular characterization in the case of bacteria (Bergey's manual 2008). Lactophenol Cotton Blue stain was used to visualize the fungal samples (Sutton and Fothergill, 1997). Microbiological analysis of all the samples was carried out using Nikon High-Resolution Microscope under 40X, 100X, 400X, and 1000X up to genus level. Further ultramicroscopic and genetic level techniques are being used for the identification of the culturable bioaerosols up to the species level.

\subsection{Monitoring Meteorological parameters:}

Meteorological data were measured in indoor sites and as well as from Delhi Pollution Control Centre (DPCC) Ambient Air Quality Monitoring System, Satyawati College Ashok Vihar Station, 110052. The figure shows the details of the study area and DPCC center involved in the present study. PM2.5, PM10, $\mathrm{CO}, \mathrm{CO} 2$, Outdoor and indoor Temperature $\left({ }^{\circ} \mathrm{C}\right)$, Relative humidity (\%), Rainfall \& Wind Speed were recorded and its relationship with aerospora was determined.

\subsection{Questionnaire Survey:}

A questionnaire survey was conducted in nearby areas of Wazirpur Industrial Area, Satyawati College, Ashok Vihar, North Delhi. A Health survey was conducted using a set of questionnaires followed by 
Satyawati College, University of Delhi, Government of India. Single-stage random sampling was performed for selecting subjects from different localities. The questionnaire form was designed to aiming to collect health \& general information of subjects and later on, approved by "Institutional Ethical Committee on Human Research" of Satyawati College, University of Delhi, Delhi and is based on MM questionnaire survey (Anderson et al 1993). Ethics Committee confirmed and approved the research, confirm that all research was performed in accordance with relevant guidelines/regulations. All authors confirm that informed consent was obtained from all participants and/or their legal guardians. Research was performed in accordance with the Declaration of Helsinki. All authors also confirm that human participants' names and other HIPAA identifiers were removed from all sections of the manuscript, including supplementary information. To achieve its form is divided into four parts, in the very first part, demographic data like name, address, gender, age, and informed consent form containing general information about the study was included. The next part of the form includes volunteer agreement and declaration of witness. The next sector of the form is the most important part (Indoor air quality Questionnaire) which also contains general information in starting and later on, it has 26 questions related to allergy, general health effects, allergens medication history, and feedback for improving air quality. In the last part, Environmental factors like temperature and humidity were measured Moreover, it also has general health parameters e.g., Sugar, Blood pressure of respondents.

2.6 Data Analysis: Minimum, maximum, mean, and standard deviation of the bioaerosols were recorded and calculated. Statical analysis and entry of questionnaires were performed using Statical Package for Social Sciences (SPSS 24) and Microsoft Excel 2019. Single way Analysis of Variance (ANOVA) was used to show the correlation between different groups (eg. Outdoor and indoor). The significance of data ( $p$-value) and odds ratio was also analyzed by using the same software. P-value was maintained at 0.05 throughout the study.

\section{Results And Discussion:}

\subsection{Demographics of the enrolled subjects in the study:}

Total 223 subjects (144 (64\%) male, 64 (29\%) female, and 15(7\%) children less than 18 years) of different age groups were enrolled in this study. The proportion of male subjects were around two-third of the total enrolled subjects. Subjects were classified on basis of age, sex, and residential area (Table 1).

Participants were randomly selected from colleges, localities, coaching centres, and other indoor places. Participants were explained about the scope, consent form, and questionnaire survey. Information and consent were taken from their parents in case of children below 18 years. All the subjects involved in the survey signed the consent designed by the Department of Environmental Studies, Satyawati College, University of Delhi. Subjects involved in the study were also informed about the biological sampling in different seasons in their houses. 
Table-1: Demographic profile of the subjects involved in the study

\begin{tabular}{|c|c|c|}
\hline \multicolumn{3}{|l|}{ Age groups } \\
\hline$<18$ years & 45 & 20.1 \\
\hline $18-40$ Years & 160 & 71.7 \\
\hline$>40$ years & 18 & 8.1 \\
\hline \multicolumn{3}{|l|}{ Gender } \\
\hline Males & 153 & 68.6 \\
\hline Females & 70 & 31.4 \\
\hline \multicolumn{3}{|c|}{ Locality of enrolled subjects } \\
\hline Residential & 110 & 49.3 \\
\hline Commercial & 60 & 27.0 \\
\hline Industrial & 53 & 23.7 \\
\hline
\end{tabular}

(Fig. 2) illustrates the various effects of indoor air quality on the health of subjects. These symptoms may directly or indirectly related to the time spent in the indoor area. As per data headache was the most dominant $(28 \%)$ health effect followed by allergies (20\%) and runny nose (13\%). Migraine and Asthma, and shortness of breath were the least common health problems among the enrolled subjects. However frequent cough, unusual thirst, sneezing, and burning of irritated eyes were also existing problems among this group of peoples. Female subjects are more likely to suffer from the symptoms for the reason of probably spending more time in the indoor areas. High indoor bacterial load and other physical features are responsible for the health problems in the students and staff in residential buildings (Andualem et al., 2019). A similar study conducted by (Madamarandawala et al., 2019) suggested that $58 \%$ of urban and $31 \%$ preschool students were suffering from at least one health effect related to the microbial air quality. Bezerra and co-workers evaluated the serum concentration in the children suffering from the allergic reactions, and levels were found to increased (Bezerra et al., 2016). A study from Kolkata, India also found that patients with atopic allergic history are more reactive towards fungal extracts (Dey et al., 2019). An epidemiological study conducted in southern India on effects of indoor air pollutants, socioeconomic, and housing characteristics on well being of children and women recorded that these factors significantly influence respiratory health and may increase the burden of respiratory illness (Rumchev et al., 2017). Findings of the pilot study conducted in Finland to assess the indoor air problems suggested that irritated, stuffy, or runny nose (20\%), itching, burning, or irritation of the eyes (17\%), and 
fatigue (16\%) were the most common symptoms in the workers. The proportion of indoor air problems in women than men similar to our present study which indicates the significance of the current study (Reijula et al 2004).

\subsection{Variation in seasonal microbial concentration in different residential places:}

Data obtained from microbial air sampling of selected indoor sites are represented in Fig. 3. The average concentration of culturable microorganisms (bacteria and fungi) in three months of December (2019-Feb 2020). By comparison of collected air samples data from different indoor sites (enrolled subjects) during spring and winter season shows microbial concentration is less in winter and high in the spring season than winter. In the winter season, bacterial concentration was highest in academies and the fungal load was highest in gas agencies. In the winter season, the highest bacterial concentration of $2366 \pm 725$ $\mathrm{CFU} / \mathrm{m} 3$ was monitored in houses and the fungal count was highest in gas agencies $2983 \pm 1106$ followed by $2961 \pm 567$ CFU/m3 in coaching academies (Fig. 3.1). Due to overcrowding and industries spring season in Delhi is hotter and more humid than in other nearby cities. Average bacterial load ranged around $2600 \mathrm{CFU} / \mathrm{m} 3$ in all microenvironments except laboratories and peaked in houses $2719 \pm 1168$ $\mathrm{CFU} / \mathrm{m} 3$. In the case of fungi, more variation was observed between different environments and the highest concentration was observed in gas agencies with $3713 \pm 1665$ CFU/m3 (Fig. 3.2). This is supposed that due to high activities of students, staff in academic places the bacterial and fungal load was high in comparison to other sites. The lowest concentration of microorganisms in all seasons was in college laboratories in the case of bacteria and as well as fungi. Microbial concentrations observed in each sampling site were compared with the other sites and with background by using one-way ANOVA and significant statical difference $(p>0.05)$ was observed. However, bacterial and Fungal counts in college lifts did not show any significant variation $(p>0.05)$ between background and sampling site. Similar results were recorded in the study conducted in a hospital for the spring and winter seasons in Pakistan (Asif et al., 2018). Previous studies reported that airborne biotic concentration of more than $1000 \mathrm{CFU} / \mathrm{m} 3$ shows microbial contamination in the environment (Golofit-Szymczak and Gorny 2010). Outdoor areas of sampling sites were used as controls in the study. Variation in microbial concentration was recorded in control samples i.e., it was higher than site samples in a few cases and lower in others. Goyer and co-workers also reported that exposure to various bacterial concentrations may affect human health directly and indirectly (Goyer et al 2001). Seasonal analysis of the microbes revealed that bacterial concentrations elevated in the houses, academies, lifts, and gas agencies. Temperature and other growth factors are favorable in Delhi in spring (March-May), which could be a possible reason behind it. The growth of two major fungal genera Aspergillus and Penicillium was highest in April and May, due to the requirement of high temperature in these fungi. High humidity and leaking conditions promote the dampness in the walls which increases the growth of the fungi on walls and other areas. (Heseltine and Rosen 2009). Fungi are often released by the hair, nail and, skin of students, which is one of the major sources of indoor contamination of the educational buildings (Wang et al., 2016). Hot and dry weather increases the spore buoyancy which causes the transport of spores from outdoor areas to longer 
distances (Kulmala et al., 1999). Ventilation plays a crucial role in maintaining the concentrations of the airborne microflora. Buildings without air conditioners (A.C.) and other anthropogenic ventilation have 1.5 times higher concentrations of bioaerosols than the buildings equipped with AC (Brągoszewska, et al., $2018 \mathrm{~b}$ ). Vegetation and traffic congestion affects the concentration of airborne microorganisms in the environments (Amarasekara et al., 2021).

\subsection{Identification of major airborne Bacteria and Fungi present in the selected Indoor Microenvironments}

Table 2 shows dominant culturable bacterial and fungal isolates from different sampling sites. More genera of bacteria and fungi were recorded from residential houses than other sampling sites (i.e., College, gas agencies, etc). The identification of fungal genera from different sites shows that Aspergillus spp., Penicillium, Rhizopus, Cladosporium, Alternaria, and Candida, were present predominantly in residential houses, and Cladosporium, Alternaria \& Aspergillus were observed in almost all the sampling sites. Aspergillus spp. and Cladosporium were common throughout all sampling sites. Staphylococcus, Micrococcus, and Streptobacillus spp. were the most dominant genera of bacteria in all the selected sites and E. coli, $G+$ cocci, Pseudomonas also recorded in few locations. Figure 4 shows the photomicrographs of the dominant microbes under the microscope under different resolutions. Variation in the type of microbes might be the presence of industrial areas, dumping sites, slaughterhouses, waste decomposition, meteorological parameters, and anthropogenic activities (Humbal et al 2019). (Husman at al 1996 and Baxi et al 2016) reported that the presence of Candida is responsible for various diseases such as sinus infections, fatigue, and Urinary tract infections. (Baxi et al 2016) also reported that the presence of Alternaria and Mucor is responsible may trigger allergic reactions and asthma. Moreover, this study also stated that the presence of Aspergillus spp. and Penicillium may cause various respiratory infections. The presence of the fungal genera Aspergillus, Alternaria, and Cladosporium cause epidemiological allergy in the inhabitants. Present and a study conducted by Priyamvada and co-workers observed the spore concentrations of the Aspergillus, and Cladosporium was significantly higher in the spring season while Alternaria was found significantly higher in the winter season (Priyamvada et al., 2017). 
Table:2. Major fungal and bacterial isolated in different microenvironments

\begin{tabular}{|l|l|}
\hline Name of the bacterial Isolates & Name of the Fungal Isolates \\
\hline Houses & \\
Staphylococcus, & Aspergillus spp. \\
Micrococcus, & Cladosporium \\
Streptococcus, & Penicillium \\
G-Bacilli, & Rhizopus \\
E. coli, & Mucor \\
Pseudomonas, & Alternaria \\
G+ Cocci, & Candida \\
Coaching Academies & \\
Staphylococcus, & Candida, \\
G+Cocci, & Aspergillus, \\
G+Bacilli & Fusarium \\
Gas Agencies & \\
Micrococcus, & Alternaria, \\
Staphylococcus, & Aspergillus \\
G+ bacilli & \\
Research Laboratories & Penicillium, \\
Streptobacillus, & Aspergillus, \\
Staphylococcus & Fusarium, \\
College Lifts & Rhizopus \\
Bacilli, & \\
Sicrococcus, & Alternaria, \\
\hline
\end{tabular}

\subsection{Influence of meteorological parameters on microbial concentrations:}

Microbial concentrations are significantly correlated with meteorological factors such as particulate matter (PM2.5, PM10), temperature, relative humidity, air exchange rates, etc Frankel et al., 2012; Mirhoseini et al., 2016; Bragoszewska et al., 2018c). Table 3 represents the description of average meteorological factors in the sampling area. The average temperature in the sampling area in the winter season remains lowest than any seasons, which results in a decline in the outdoor fungal and bacterial counts. Indoor and outdoor microbial ratio $(\mathrm{I} / \mathrm{O})$ remains > 1.5 in except laboratories in the case of fungi while bacterial counts fluctuate. The Spring season in Delhi becomes dry and the temperature becomes significantly higher in April-May. 
Table 3

Description of the meteorological parameters of the sampling areas (AQI Data source: Ambient Air quality monitoring system (DPCC) Ashok Vihar, Delhi)

\begin{tabular}{|lllllll|}
\hline Season & Winter & \multicolumn{5}{c|}{ Spring } \\
\hline Month & December & January & February & March & April & May \\
\hline Temperature & 14.1 & 18.4 & 21.9 & 23.1 & 29.9 & 30.2 \\
\hline Relative Humidity (RH) & 63.2 & 58.7 & 63.6 & 43 & 48.4 & 36.6 \\
\hline AQI (PM 2.5) & 414 & 362 & 290 & 190 & 187 & 249 \\
\hline
\end{tabular}

Culturable bacterial spore count of indoor areas exceeds outdoor counts except for laboratories. In the case of fungi, indoor bioaerosols were higher than outdoors in houses, academies, and gas agencies. A polish study shows the positive correlation between the coarse particulate matter with bioaerosol concentration but it was also observed that temperature has different effects in each season (Bragoszewska et al., 2018c). Microbial exposures are significantly affected by seasons which are influenced by temperature, relative humidity, and exchange rates (Frankel et al., 2012).

Isolation, evaluation, and characterization are very necessary for controlling microbial contamination in indoor environments. Human activities, poor ventilation, and degradation of waste products are major sources of these contaminants (Karmakar et al., 2020). In this study, we have particularly focused on the biological sampling of the microenvironments which are crucial for the spread and propagation of airborne diseases but the least attention is paid on these. Current data represents that the microbial load of indoor sites changes season to season and time to time on behalf of different conditions. Collected data has been also compared with the previous studies and found as presented by different authors in the past (Adhikari et al., 2017; Chuang et al., 2014). This study is very important as most of the time of the residents is spent in indoor places and they face various problems related to microbial indoor air quality (Madamarandawala et al., 2019; Rautiainen et al., 2019; Herr et al., 2003; Dey et al., 2019; Wu et al., 2018). In our study, we noticed that headaches and allergies are the two major problems reported in subjects. There are sufficient clinical and experimental results that are these reactions are associated with dampness and elevated indoor mold concentrations (WHO, 2009).

Few studies were carried out in Delhi to assess the biological pollution at different sites. Most of the studies were focused on the educational institutes, libraries, dumping sites, etc. (Lal et al., 2017; Srivastava et al., 2012; Agarwal et al, 2016; Balyan et al., 2017; Kumar et al., 2013). Sharma and coworkers performed a study in the houses of patients suffering from asthma/allergies and reported $(110,091)$ and $(107,070)$ fungal colonies per cubic meter area in indoor and outdoor areas respectively (Sharma et al., 2011). Bacterial sampling conducted in a slum area near Jawaharlal Nehru University (South Delhi) reported a high number of bacterial aerosols ranging from 0.43-3.35 x $107 \mathrm{CFU} / \mathrm{m} 3$, which is significantly higher than other similar studies (Kumar et al., 2013). Another study performed in JNU libraries recorded total bioaerosols within the range of $911-1460 \mathrm{CFU} / \mathrm{m} 3$ and $2550-3110 \mathrm{CFU} / \mathrm{m} 3$ for bacteria and fungi respectively (Ghosh et al., 2013). Ambient bioaerosol concentration measured between 
(1740-3224 CFU/m3) for fungi and (1990-9428 CFU/m3) in case of bacteria in different areas of Delhi. In general, this study also observed that most bioaerosols are found in stage 4 (2.1-3.3 $\mu \mathrm{m})$, stage $5(2.1-2.2 \mu \mathrm{m})$, these particles are capable of penetrating the lower parts of the lungs (Lal et al., 2017).

\section{Conclusion:}

The major culturable bioaerosols isolated and identified in the current study belong to the opportunistic pathogens category. High concentrations of the microbes were observed in indoor areas in comparison to outdoors, which indicates the relation of respiratory health problems with these. Headaches are allergies are the major symptoms observed in inhabitants. To date, only limited studies are available about seasonal bioaerosol monitoring in Delhi. Hence, sampling data collected from indoor sites in different seasons will help to know more about the seasonal health problems. Data generated by this study will help to give knowledge about the bio-contaminants in indoor areas responsible for adverse health effects. Data generated from this study may contribute to the promotion and implementation of preventative public health programs and the formulation of recommendations aimed at providing healthier outdoor environments. It will also help to standardize protocols so that how we can reduce the level of biological pollution.

\section{Declarations}

Acknowledgements-This work was financially supported by Science and Engineering Research Board, Department of Science and Technology (SERB-DST), New Delhi, India.

Ethics approval and consent to participate: Name of the Ethical committee as "Institutional Ethical Committee for Human Research" of Satyawati College, University of Delhi, Delhi provided approval for conducting the study on 8 May 2018. All authors confirm that informed consent was obtained from all participants and/or their legal guardians in case of minors.

Consent for Publication: Not Applicable

Competing Interests: The authors declare that they have no competing interests.

Conflict of Interest: Authors declare that they have no conflict of interest.

Authors Contributions: P K performed the experiments and wrote the manuscript. A B S edited and finally approved the manuscript. R S designed, analysed and supervised the study.

\section{References}

1. Adhikari, A., Kurella, S., Banerjee, P., \& Mitra, A. (2017). Aerosolized bacteria and microbial activity in dental clinics during cleaning procedures. Journal of Aerosol Science, 114, 209-218. 
2. Agarwal S, Mandal P, Srivastava A. Quantification and Characterization of Size-segregated Bioaerosols at Municipal Solid Waste Dumping Site in Delhi. Procedia Environmental Sciences 35 (2016) $400-407$

3. Amarasekara, R.W.K., Vithanage, M., Samaraweera, P. et al. Effect of traffic congestion and vegetation on airborne bacteria in a city of a developing country. Air Qual Atmos Health (2021). https://doi.org/10.1007/s11869-021-01001-1

4. Anderson A. A, New Sampler for the collection Sizing and Enumeration of Viable airborne Partclies, 1958, Journal of Bacteriology, 76(5),471-484

5. Andersson, K., Stridh, G., Fagerlund, I. amd Aslaksen, W. 1993. "The MM-questionnaires - A tool when solving indoor climate problems". Department of Occupational and Environmental Medicine, Örebro University Hospital, Örebro, Sweden. Retrieved February 24, 2020, from http://www.orebroll.se/upload/USO/YMK/Dokument/Reference3eng.pdf.

6. Andualem, Z., Gizaw, Z., Bogale, L. et al. Indoor bacterial load and its correlation to physical indoor air quality parameters in public primary schools. Multidiscip Respir Med 14, 2 (2019). https://doi.org/10.1186/s40248-018-0167-y

7. Asif $A$, Zeeshan M, Hashmi I et al., Microbial quality assessment of indoor air in a large hospital building during winter and spring seasons. Building and Environment 135 (2018) 68-73

8. Aydogdu, H., Asan, A. \& Tatman Otkun, M. Indoor and outdoor airborne bacteria in child day-care centers in Edirne City (Turkey), seasonal distribution and influence of meteorological factors. Environ Monit Assess164, 53-66 (2010). https://doi.org/10.1007/s10661-009-0874-0

9. Baxi SN, Portnoy JM, Larenas-Linnemann D, Phipatanakul W (2016) Exposure and health effects of Fungi on humans. J Allergy Clin Immunol 4(3):396-404

10. Bragoszewska E, and Biedron I, Indoor Air Quality and Potential Health Risk Impacts of Exposure to Antibiotic Resistant Bacteria in an Office Rooms in Southern Poland, (2018 a) J. Env. Res. Pub. Health, DOI: 10.3390/ijerph15112604

11. Brągoszewska, E., Biedroń, I., Kozielska, B. et al. Microbiological indoor air quality in an office building in Gliwice, Poland: analysis of the case study. Air Qual Atmos Health 11, 729-740 (2018). https://doi.org/10.1007/s11869-018-0579-z

12. Brągoszewska, E., Pastuszka, J.S. Influence of meteorological factors on the level and characteristics of culturable bacteria in the air in Gliwice, Upper Silesia (Poland). Aerobiologia 34, 241-255 (2018 c). https://doi.org/10.1007/s10453-018-9510-1

13. Chirca loana, The hospital environment and its microbial burden: challenges and solutions. Future Microbiol. (2019) 14(12), 1007-1010.

14. Cho SY, Myong JP, Kim WB, et al. Profiles of Environmental Mold: Indoor and Outdoor Air Sampling in a Hematology Hospital in Seoul, South Korea. Int J Environ Res Public Health. 2018;15(11):2560. Published 2018 Nov 15. doi:10.3390/ijerph15112560

15. Chuang, C.-Y., Cheng, H.-C., Yang, S., Fang, W., Hung, P.-C., \& Chuang, S.-Y. (2014). Investigation of the spreading characteristics of bacterial aerosol contamination during dental scaling treatment. Journal 
of Dental Sciences, 9(3),294-296.

16. de Barros Bezerra, G.F., Haidar, D.M.C., da Silva, M.A.C.N. et al. IgE serum concentration against airborne fungi in children with respiratory allergies. Allergy Asthma Clin Immuno/12, 18 (2016). https://doi.org/10.1186/s13223-016-0128-y

17. Dey, D., Ghosal, K. \& Bhattacharya, S.G. Aerial fungal spectrum of Kolkata, India, along with their allergenic impact on the public health: a quantitative and qualitative evaluation. Aerobiologia 35, 15-25 (2019). https://doi.org/10.1007/s10453-018-9534-6

18. Fernstrom A, Goldblatt M. Aerobiology and its role in the transmission of infectious diseases. J Pathog. 2013;2013:493960. doi: 10.1155/2013/493960. Epub 2013 Jan 13. PMID: 23365758; PMCID: PMC3556854.

19. Frankel M, Bekö G, Timm M, Gustavsen S, Hansen E W, Anne Mette Madsen Seasonal Variations of Indoor Microbial Exposures and Their Relation to Temperature, Relative Humidity, and Air Exchange Rate. Applied and Environmental Microbiology, Nov 2012, 78 (23) 8289-8297;

20. Fung F. \& Hughson W G, Health Effects of Indoor Fungal Bioaerosol Exposure. Applied Occupational and Environmental Hygiene 2001; 18:7;535-544.

21. Ghanizadeh F, Godini H. A review of the chemical and biological pollutants in indoor air in hospitals and assessing their effects on the health of patients, staff and visitors. Reviews on environmental health, 2018, 33.3: 231-245.

22. Ghosh B., Lal H., Kushwaha R., et al (2013) Estimation of bioaerosol in indoor environment in the university library of Delhi. Sustain. Environ. Res. 23:199-207

23. Golofit-Szymczak, M; Gorny, R.L. Bacterial and fungal aerosols in air-conditioned office buildings in Warshaw, Poland-the winter season. J. Occup. Saf. Ergon. 2010,16,165-476.

24. Gupta S, Pereira B, Singh A B. Survey of airborne culturable and non-culturable fungi at different sites in Delhi metropolis. Asian Pacific journal of allergy and immunology,1993;(11)19-28

25. Herr CEW, zur Nieden A, Jankofsky M, et al Effects of bioaerosol polluted outdoor air on airways of residents: a cross sectional study

26. Heseltine E, Rosen J (eds) (2009) WHO guidelines for indoor air quality: dampness and mould. WHO Regional Office Europe, København

27. Humbal, C., Joshi, S.K., Trivedi, U.K. et al.Evaluating the colonization and distribution of fungal and bacterial bio-aerosol in Rajkot, western India using multi-proxy approach. Air Qual Atmos Health 12, 693-704 (2019). https://doi.org/10.1007/s11869-019-00689-6

28. Karmakar, B., SenGupta, K., Kaur, A. et al.Fungal bio-aerosol in multiple micro-environments from eastern India: source, distribution, and health hazards. SN Appl. Sci. 2, 565 (2020). https://doi.org/10.1007/s42452-020-2323-1

29. Khan H A A, Karuppayil M S. Fungal pollution of indoor environments and its management. Saudi J Biol Sci. 2012;19(4):405-426. doi:10.1016/j.sjbs.2012.06.002 
30. Kulmala M, Asmi A, Pirjola L (1999) Indoor air aerosol model: the effect of outdoor air, filtration and ventilation on indoor concentrations. Atmos Environ 33:2133-2144. https ://doi.org/10.1016/S1352 $-2310(99) 00070-9$

31. Kumar, B., Gupta, G., Singh, S.B., \& Kulshrestha, U. (2013). Study of Abundance and Characterization of Culturable Bioaerosol at Delhi , India. International Journal of Environmental Engineering and Management., 4,(3) (2013), 219-26

32. Kumari, P., Woo, C., Yamamoto, N. et al.Variations in abundance, diversity and community composition of airborne fungi in swine houses across seasons. Sci Rep 6, 37929 (2016). https://doi.org/10.1038/srep37929

33. Madamarandawala, P., Weerasinghe, Y., Pathiraja, D. et al.Impact of microbial air quality in preschools on paediatric respiratory health. SN Appl. Sci. 1, 1280 (2019). https://doi.org/10.1007/s42452-019-1306-6

34. Madhwal S, Prabhu V, Sundriyal S, Shridhar V. Ambient bioaerosol distribution and associated health risks at a high traffic density junction at Dehradun city, India. Environ Monit Assess. 2020 Feb 22;192(3):196. doi: 10.1007/s10661-020-8158-9. PMID: 32086610; PMCID: PMC7087893.

35. Melody SM, Bennett E, Clifford HD, Johnston FH, Shepherd CC, Alach Z, Lester M, Wood LJ, Franklin $\mathrm{P}$, Zosky GR. A cross-sectional survey of environmental health in remote Aboriginal communities in Western Australia. Int J Environ Health Res. 2016 Oct-Dec;26(5-6):525-35. doi:

10.1080/09603123.2016.1194384. Epub 2016 Jun 7. PMID: 27267619.

36. Moldoveanu A M, Biological Contamination of Air in Indoor Spaces, Current Air Quality issues http://dx.doi.org/10.5772/59727, 489-514, 2015. Occupational and Environmental Medicine 2003;60:336-342.

37. Park, J., Ichijo, T., Nasu, M. et al.Investigation of bacterial effects of Asian dust events through comparison with seasonal variability in outdoor airborne bacterial community. Sci Rep 6, 35706 (2016). https://doi.org/10.1038/srep35706

38. Priyamvada H, Singh RK, Akila M, Ravikrishna R, Verma RS, Gunthe SS. Seasonal variation of the dominant allergenic fungal aerosols - One year study from southern Indian region. Sci Rep. 2017 Sep 11;7(1):11171. doi: 10.1038/s41598-017-11727-7. PMID: 28894264; PMCID: PMC5593913.

39. Reijula, K. and Sundman-Digert, C. 2004, Assessment of Indoor Air problems at Work with questionnaire. Journal of Occupational and Environmental Medicine 61,33-38

40. Reynolds, S.J.; Black, D.W.; Borin, S.S.; Breuer, G.; Burmeister, L.F.; Fuortes, L.J.; Smith, T.F.; Stein, M.A.; Subramanian, P.; Thorne, P.S.; et al. Indoor environmental quality in six commercial office buildings in the midwest United States. Occup. Environ. Hyg. 2001, 16, 1065-1077

41. Rumchev K, Zhao Y, Spickett J. Health Risk Assessment of Indoor Air Quality, Socioeconomic and House Characteristics on Respiratory Health among Women and Children of Tirupur, South India. Int J Environ Res Public Health. 2017;14(4):429. Published 2017 Apr 17. doi:10.3390/ijerph14040429

42. Sharma, Rashmi et al. "Indoor fungal concentration in the homes of allergic/asthmatic children in Delhi, India." Allergy \& rhinology (Providence, R.I.) vol. 2,1 (2011): 21-32. doi:10.2500/ar.2011.2.0005 
43. Srikanth P, Sudharsanam S, Steinberg R. Bio-aerosols in indoor environment: composition, health effects and analysis. Indian J Med Microbiol. 2008 Oct-Dec;26(4):302-12. doi: 10.4103/02550857.43555. PMID: 18974481.

44. Srivastava, A., Singh, M. \& Jain, V.K. Identification and characterization of size-segregated bioaerosols at Jawaharlal Nehru University, New Delhi. Nat Hazards 60, 485-499 (2012). https://doi.org/10.1007/s11069-011-0022-3

45. SuttonDA, Fothergill A W. Guide to Clinically Significant Fungi Paperback - Import, 1 November 1997

46. Švajlenka J, Kozlovská M, Pošiváková T(2017). Assessment and biomonitoring indoor environment of buildings, International Journal of Environmental Health Research, 27:5, 427439, DOI: 1080/09603123.2017.1373276

47. Wang X, Liu W, Huang C, Cai J, Shen L, Zou Z, Lu R, Chang J, Wei X, Sun C, Zhao Z (2016) Associations of dwelling characteristics, home dampness, and lifestyle behaviors with indoor airborne culturable fungi: on-site inspection in 454 Shanghai residences. Buil Environ 102:159-166. https ://doi.org/10.1016/j.build env.2016.03.010

48. Indoor Air Quality: Biological Contaminants: Report on a Who Meeting, Rautavaara. Volume 31 World Health Organization Regional Office for Europe; Copenhagen, Denmark: 1988.

49. Wu Y, Lu Y, Chou D C. Indoor air quality investigation of a university library based on field measurement and questionnaire survey, J. Low-Carbon Technologies 2018, 13, 148-160

\section{Figures}

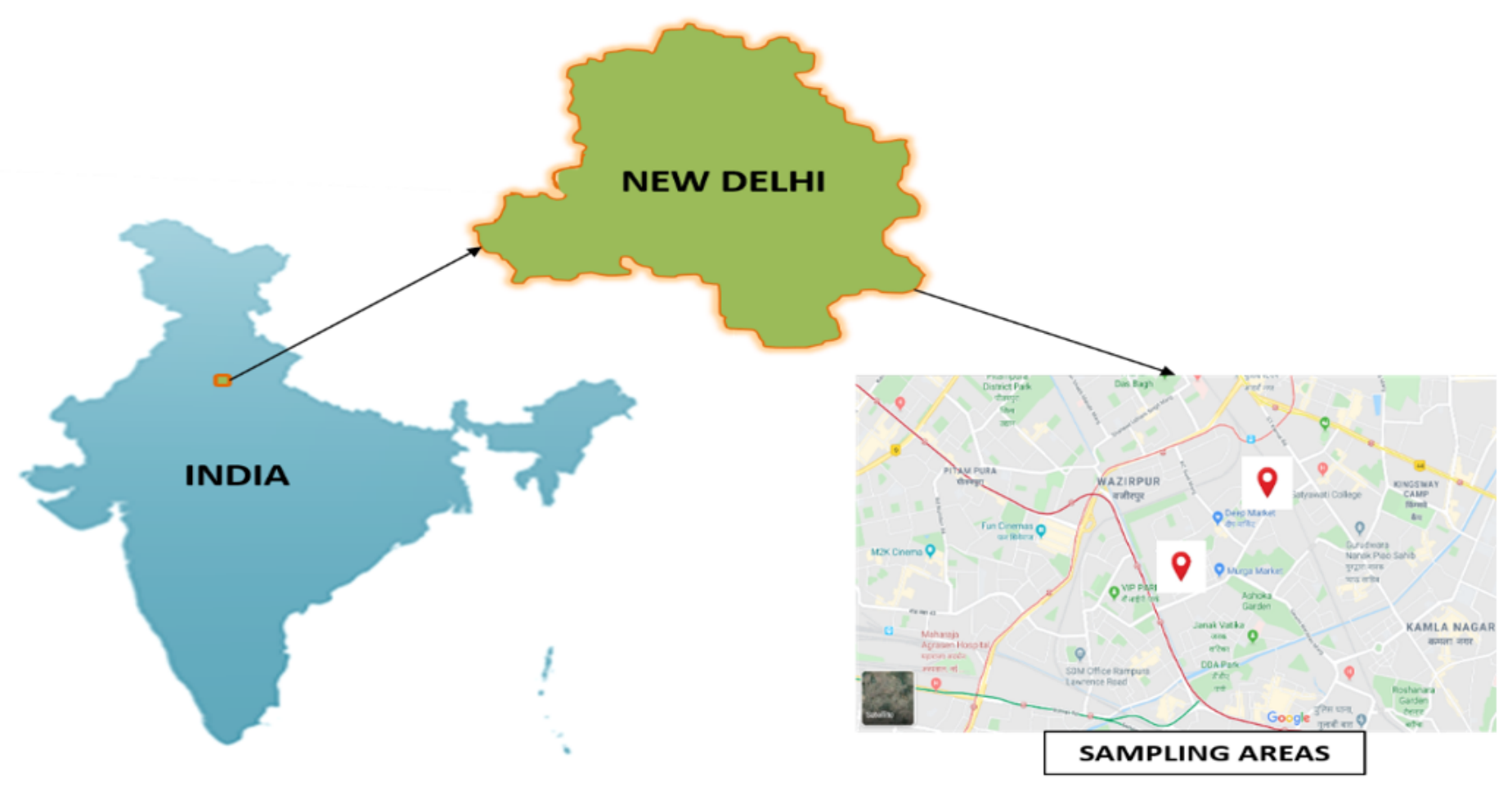

Figure 1 
Geographical location of the biological sampling sites

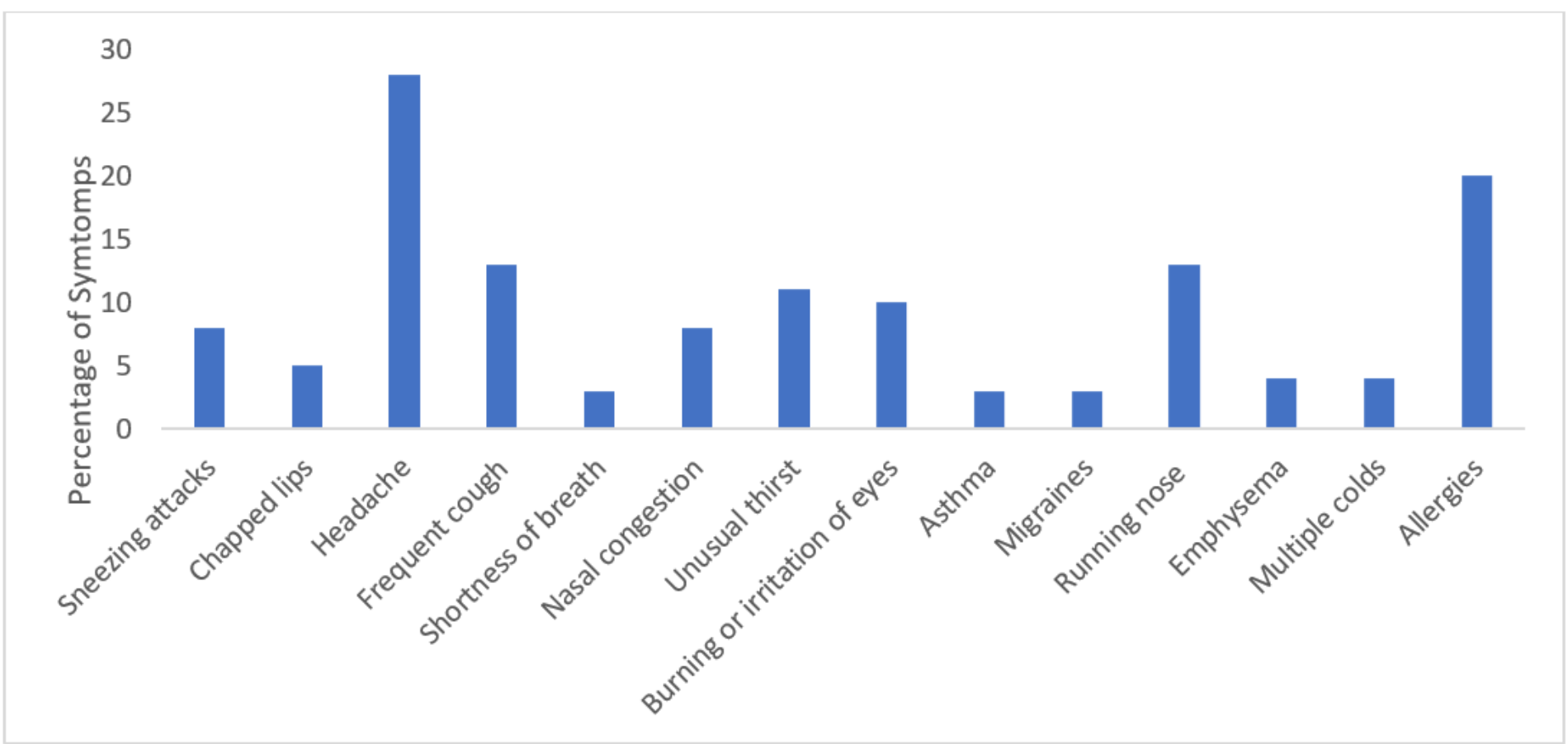

Figure 2

Occurrence of the respiratory health effects from exposure indoor microbial air 


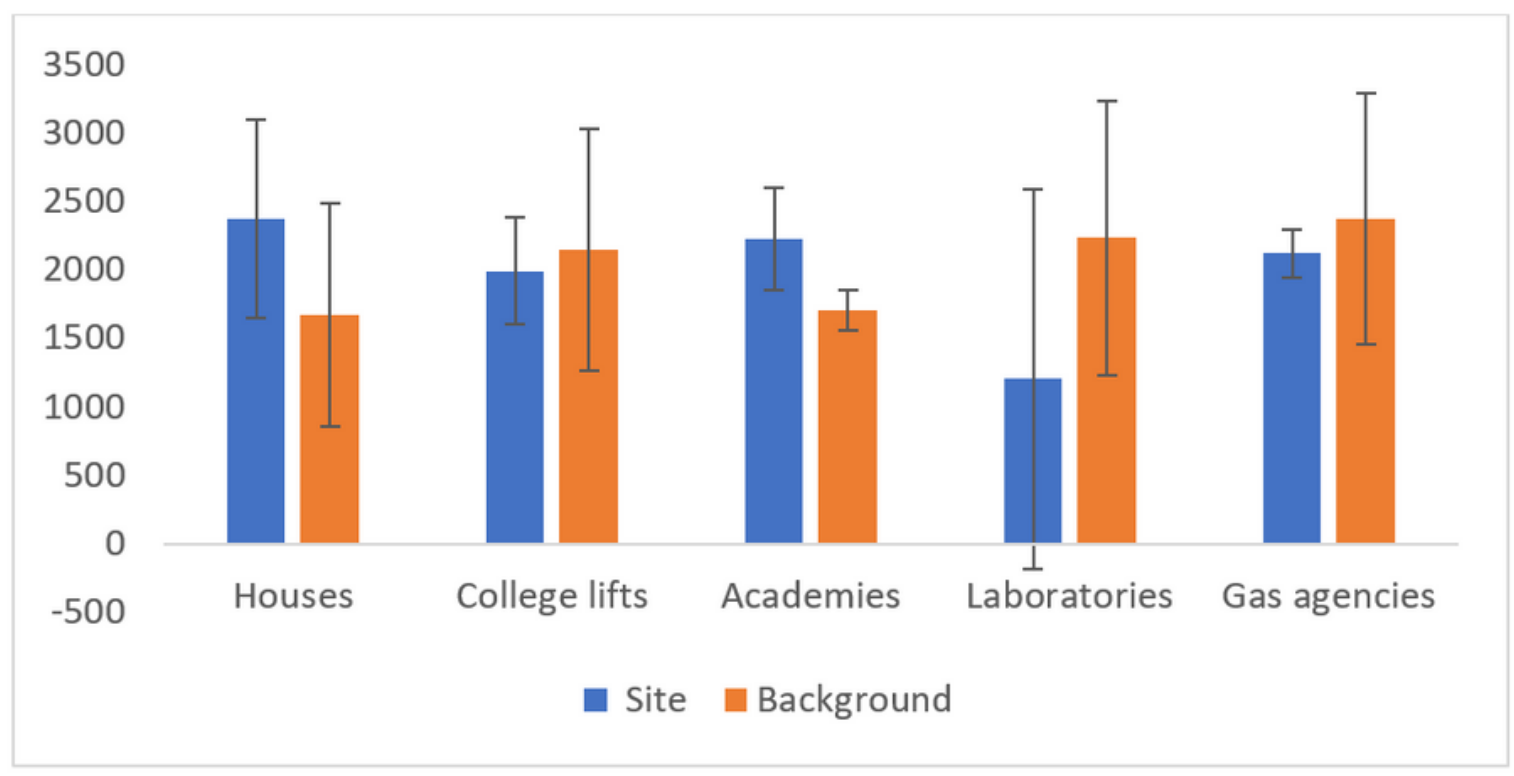

\section{a. Bacteria}

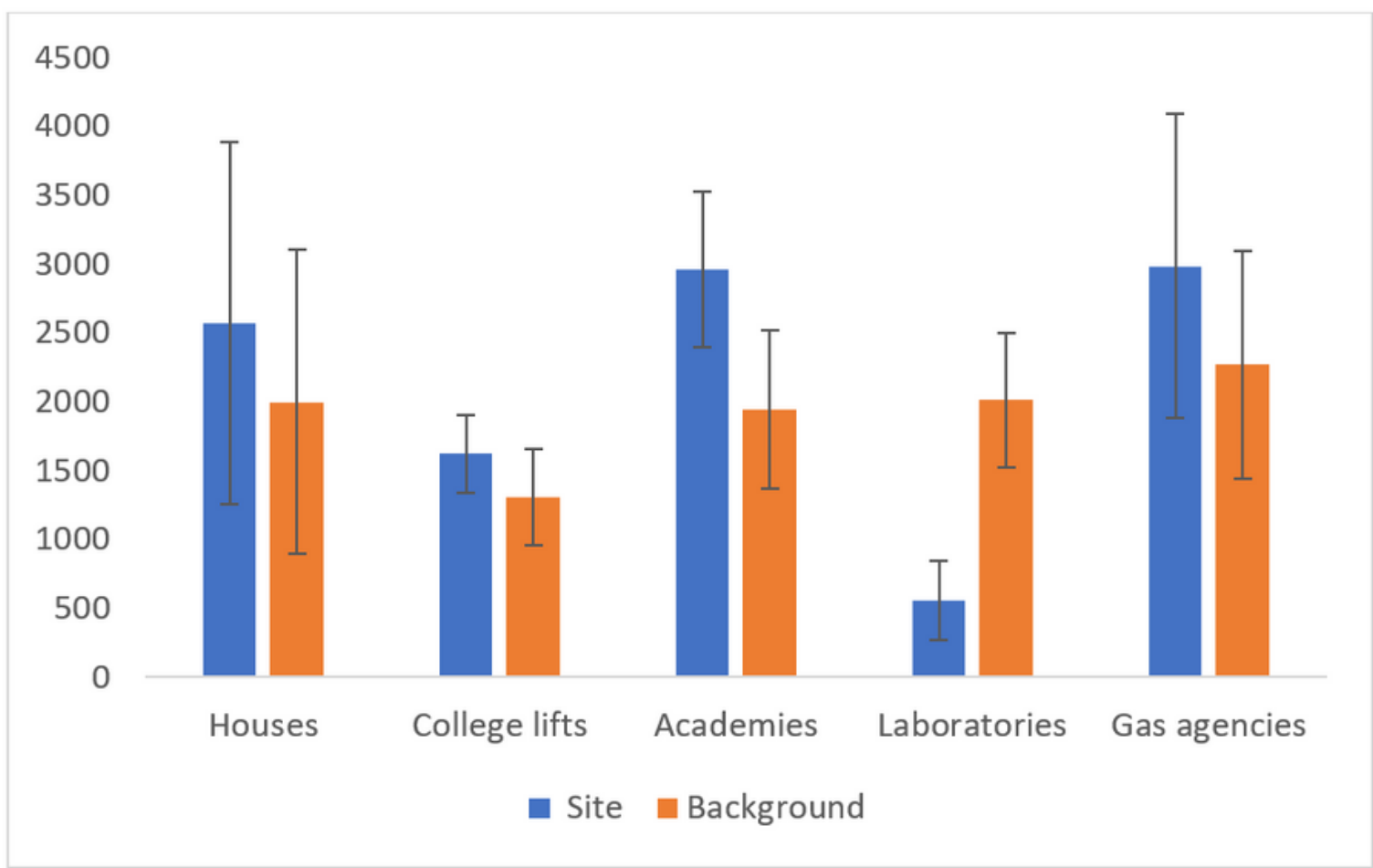

b. Fungi

Figure 3

Average microbial concentration (Bacteria and Fungi) in winter season (Dec-Feb 2018-19) 


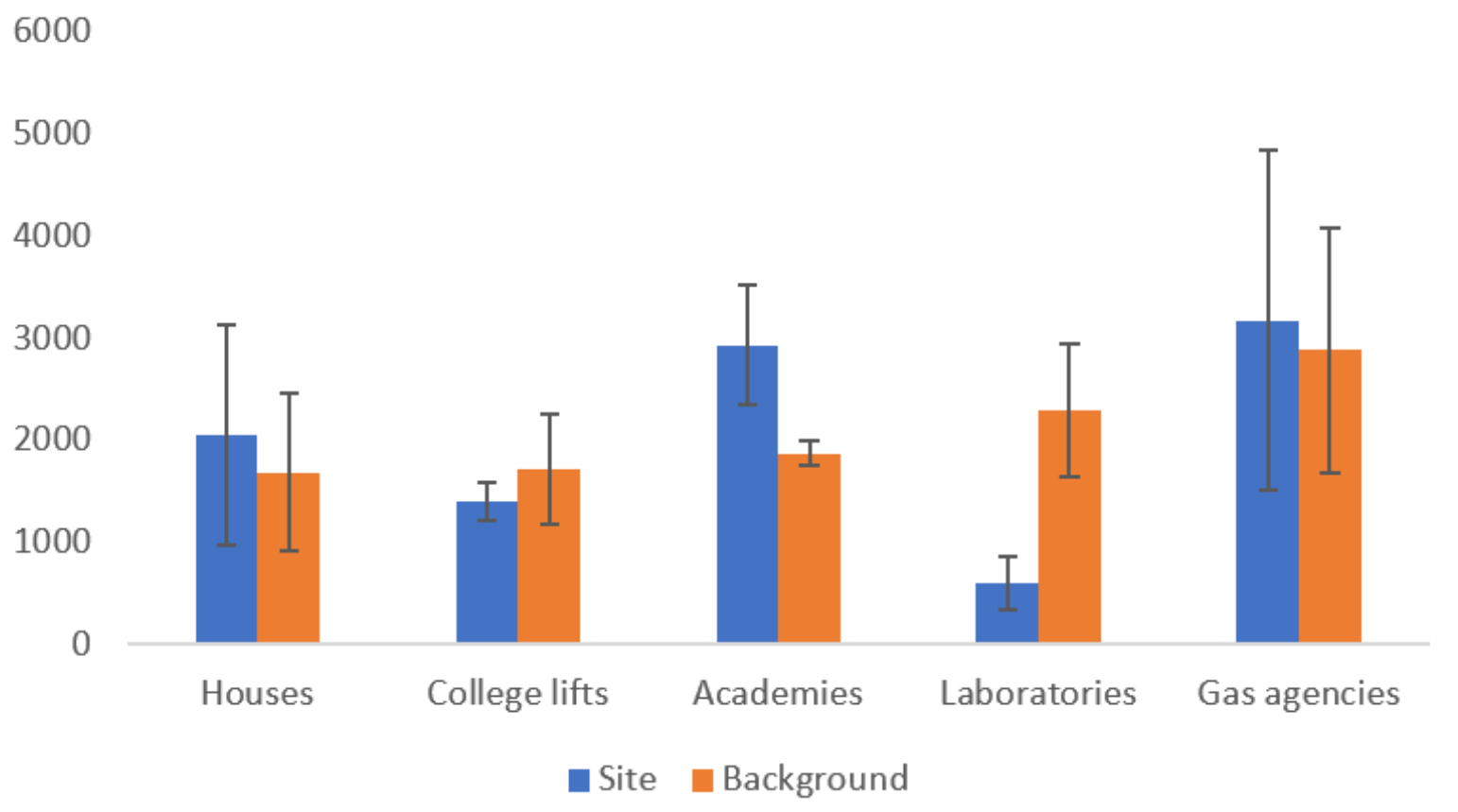

\section{a. Fungi}

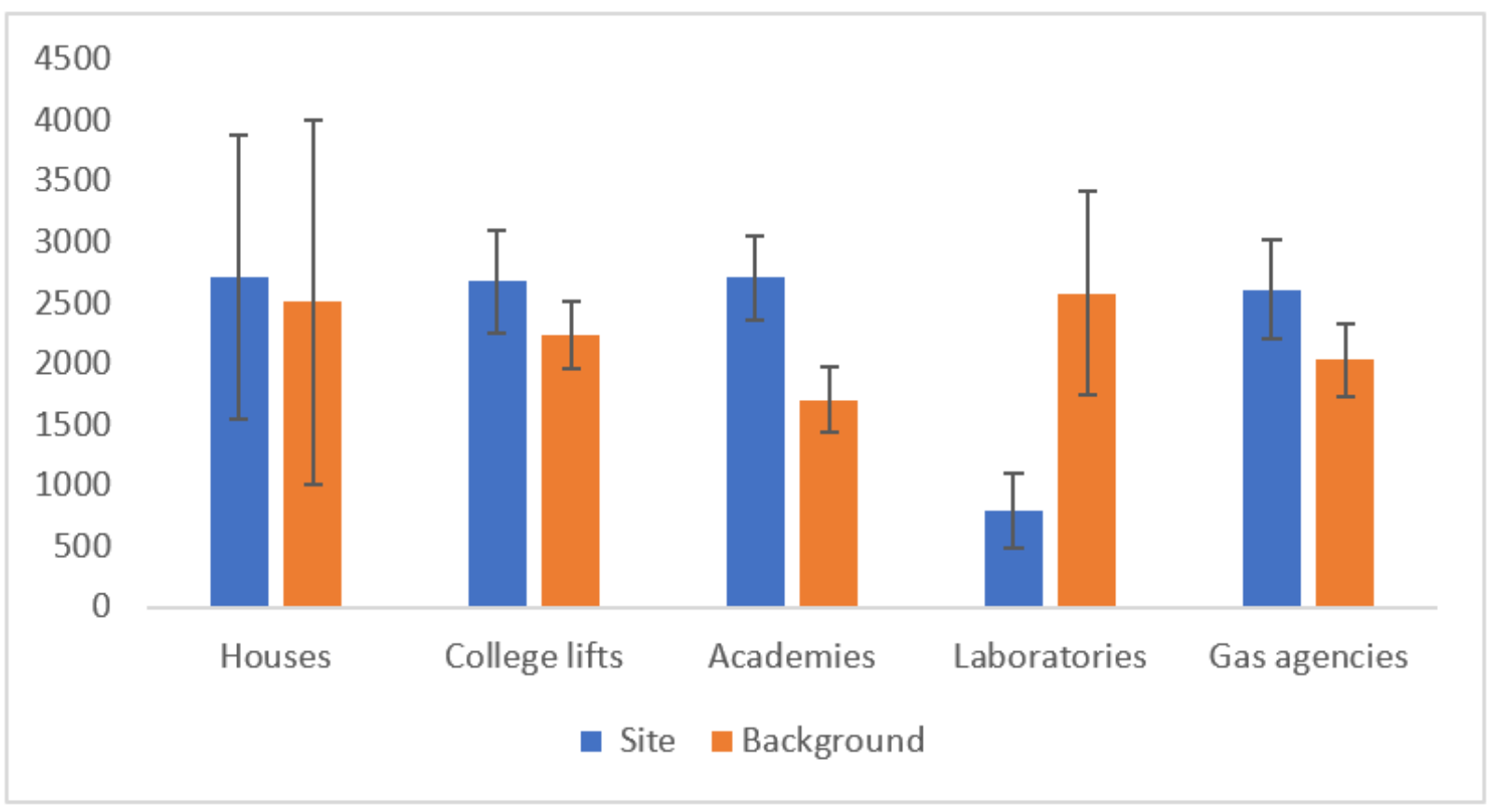

\section{b. Bacteria}

\section{Figure 4}

Average microbial concentration (Bacteria and Fungi) in spring season (Mar-May 2019) 


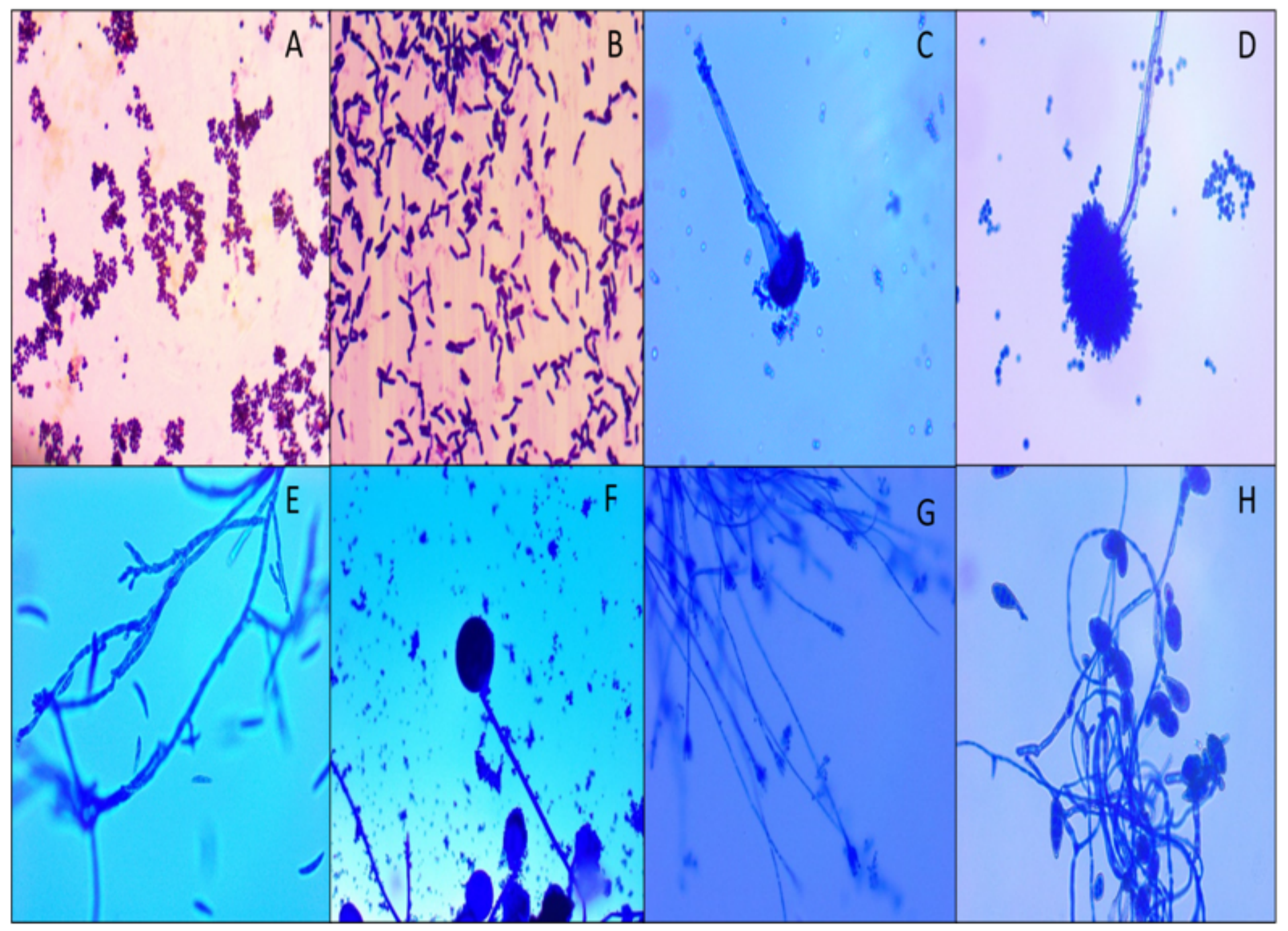

Figure 5

Photomicrographs of indoor microflora: A. G+ cocci (1000X), B. G+ Bacilli (1000X), C. Aspergillus (400X), D. Aspergillus (400X), E. Fusarium (400X), F. Rhizopus (400X), G. Penicillim (100X), H. Alternaria (100X) 